\title{
The role of ruminations in the relation between personality and positive posttraumatic changes resulting from struggling with cancer
}

\section{BACKGROUND}

Cognitive activity, including event-related ruminations, and personality features play an essential role in the occurrence of positive outcomes of experienced trauma. The study investigated the role of ruminations, treated both in terms of stable disposition (trait-like rumination), and about the event, in the relationship between personality dimensions and posttraumatic growth (PTG).

\section{PARTICIPANTS AND PROCEDURE}

Sixty people, aged $18-78$ years $(M=50.40, S D=17.74)$, who had experienced malignant tumours in the craniofacial area were examined. The majority of respondents (68.30\%) were women. The Posttraumatic Growth Inventory (PTGI), the NEO-Five Factor Inventory (NEO-FFI), the Rumination-Reflection Questionnaire (RRQ), and the Event Related Rumination Inventory (ERRI) were used in the study.

\section{RESULTS}

Conscientiousness is positively and neuroticism is negatively related to PTG. Reflection and both types of rumi- nations about the experienced event, i.e. intrusive and deliberate, are positively associated with positive posttraumatic changes. The multiple mediation analysis (double mediation model) indicated that intrusive ruminations about the experienced event and reflection (reflective rumination), treated in terms of disposition, play the role of suppressors in the relation between neuroticism and PTG. Neuroticism lowers the ability to perceive the positive effects of experienced trauma, but promotes intrusive ruminating, which, in combination with reflection, increases the level of PTG.

\section{CONCLUSIONS}

Ruminations seem to play a more important role in occurrence of PTG than personality. Ruminations about the experienced situation are more significant than trait-like rumination for the occurrence of positive posttraumatic changes.

KEY WORDS

posttraumatic growth; personality; ruminations; cancer

ORgANization - Institute of Psychology, University of Lodz, Lodz, Poland

AUthors' contributions - A: Study design - B: Data collection - C: Statistical analysis - D: Data interpretation .

E: Manuscript preparation · F: Literature search · G: Funds collection

CorresPonding Author - Prof. Nina Ogińska-Bulik, Institute of Psychology, University of Lodz, 10/12 Smugowa Str., 91-433 Lodz, Poland, e-mail: noginska@uni.lodz.pl

TO CITE THIS ARTICLE - Ogińska-Bulik, N. (2018). The role of ruminations in relation between personality and positive posttraumatic changes resulting from struggling with cancer. Health Psychology Report, 6(4), 296-306. https://doi. org/10.5114/hpr.2019.77176

RECEIVED 08.10.2017 · REVIEWED 17.04.2018 · ACCEPTED 03.07.2018 · PUBLISHED 23.07.2018 


\section{BACKGROUND}

\section{POSITIVE CONSEQUENCES OF THE STRUGGLE WITH CANCER}

Cancer is regarded as a life-threatening disease, and as such may be treated as a potentially traumatic event. In many people experience of cancer is related to occurrence of posttraumatic stress disorder (PTSD) symptoms (Cordova, Studs, Hann, Jacobsen, \& Andrykowski, 2000; Shelby \& Golden-Kreutz, 2008). However, the struggle with cancer can also result in the development of positive changes, expressed in posttraumatic growth (PTG). Posttraumatic growth manifests as positive changes in self-perception, relations with others and philosophy of life (Tedeschi \& Calhoun, 1996, 2004; Ogińska-Bulik, 2015).

Many studies have confirmed the presence of PTG among oncological patients (Bellizzi \& Blank, 2006; Carboon, Anderson, Pollard, Szer, \& Seymour, 2005; Cormio, Muzzatti, Romito, Mattioli, \& Annunziata, 2017; Mystakidou, Tsilika, Parpa, Galanos, \& Vlahos, 2008; Ogińska-Bulik, 2010, 2016; Park, Chmielewski, \& Blank, 2010; Zwahlen, Krsna Rajandram, \& Jenewein, 2016). Among the many factors determining the positive effects of posttraumatic changes, an important role is played by the existing personality traits and the degree of cognitive engagement in processing the trauma, particularly the presence of ruminations about the experienced event.

\section{PERSONALITY, RUMINATIONS AND POSTTRAUMATIC GROWTH}

Among the personality dimensions comprising the Big Five model, extraversion and openness to new experiences have been found to have the greatest influence on the emergence of PTG (Linley \& Joseph, 2004; Tedeschi \& Calhoun, 1996). Other studies have also indicated that agreeableness (Tashiro \& Frazier, 2003) and conscientiousness (Karanci et al., 2012) are also significant. The role of neuroticism in occurrence of positive posttraumatic changes is not clear. Most studies (Linley \& Joseph, 2004; Ogińska-Bulik, 2015, 2017a) have indicated that neuroticism has a negative influence on PTG, in that it inhibits the development of posttraumatic changes. There are also studies indicating the lack of a relationship between neuroticism and PTG (An, Ding, \& Fu, 2017; Shakespeare-Finch, Gow, \& Smith, 2005). This suggests that the relationship between personality, and especially its dimension of neuroticism and PTG, is complex.

An important role in the development of positive posttraumatic changes is also played by the cognitive activity of the individual, particularly the process of ruminating (Calhoun \& Tedeschi, 2006; Calhoun, Cann, \& Tedeschi, 2010; Ogińska-Bulik, 2015;
Tedeschi \& Calhoun, 1996, 2004). As a result of the event, the individual not only experiences negative emotions, but also considers and remembers the experienced event, discusses it, analyses it and gradually gives it new meaning. This type of cognitive activity is primarily intended to enable the cognitive processing of the trauma, which in turn can lead to the prevalence of positive changes.

Rumination is a complex concept. Most often it is understood as contemplation or "chewing over" specific content, which often occurs for no apparent reason. Nolen-Hoeksema (2000) considers ruminative thinking to be a passive process which serves to focus attention on perceived negative emotions. From this perspective, rumination is associated primarily with the occurrence of symptoms of pathology, particularly depression and anxiety. Ruminating may be regarded as a process involving repeated thoughts about the experienced traumatic event, which may be of a negative, neutral or even positive character (Calhoun \& Tedeschi, 1998).

Trauma-related rumination indicates repetitive thinking of an experienced event and its consequences (Michael, Halligan, Clark, \& Ehlers, 2007). This process includes two types of rumination (Calhoun \& Tedeschi, 2006; Calhoun, Cann, \& Tedeschi, 2010; Cann et al., 2011). One, known as intrusive rumination, is more destructive. It is composed of automatically occurring thoughts that the individual is not able to control, and which are not linked to attempts to solve the problem. The second form, deliberate rumination, is more constructive. It encourages the individual to analyse the situation, and to identify ways to resolve it. As indicated by the model of posttraumatic growth (Calhoun \& Tedeschi, 2006; Calhoun, Cann, \& Tedeschi, 2010), both types of ruminations are significant for the occurrence of positive posttraumatic changes, but deliberate ruminations seem to play the more important role. Ruminating is needed to re-examine the beliefs and rebuild the posttraumatic world (Janoff-Bulman, 2006).

A body of available data, although not all of it, confirmed that ruminating about the experienced situation, especially deliberate rumination, is related to the occurrence of PTG following the experience of cancer (Chan, Ho, Tedeschi, \& Leung, 2011; Morris \& Shakespeare-Finch, 2011). However, there are also studies which indicate a lack of any relationship between rumination and PTG, or even a negative relationship between the variables. Long-term studies on leukaemia patients have found that intrusive ruminating occurring during the course of treatment does not predict the occurrence of PTG at the end of treatment (Carboon et al., 2005). Similar results have been obtained in groups of patients with colorectal cancer (Salsman, Segerstrom, Brechting, Carlson, \& Andrykowski, 2009). In turn, in another study of cancer patients (Park, Chmielewski, \& Blank, 2010) reported
The role of ruminations in the relation between personality and PTG 
a negative relationship between intrusive rumination and the occurrence of positive changes following the trauma. These equivocal results of studies into the relationship between rumination and the outcomes of trauma associated with the experience of cancer have encouraged further exploration.

Ruminating can also be considered as a relatively stable tendency to think (meditate, contemplate) about oneself and the world, regardless of the experienced events. In this case, the rumination is treated as a relatively stable personality property (dispositional ruminating, a trait-like rumination, ruminating style). Such an understanding of the ruminations are presented, among others, by Trapnell and Campbell (1999). The authors distinguished two types of mental activity, one of which helps in its functioning: reflection (positive rumination) and rumination. Reflection is treated as a form of private self-awareness, motivated by cognitive curiosity. Rumination, on the other hand, is a form of self-consciousness, which is characterized by an involuntary, long-term concentration on one's thoughts, usually related to the past. This type of cognitive activity is most often the result of perceived risk, losses, feelings of injustice towards one's self and is associated with neuroticism. These two types of general mental activity refer to the non-adaptive rituals (typical chattering) and adaptive, which often combine with the positive qualities of the individual, such as openness to experience or ability to solve problems (Joorman, Dkane, \& Gotlib, 2006; Radoń, 2014).

The research on ruminations and reflection, treated in terms of disposition, pointed to greater adaptability and higher well-being of people with reflection (Słowińska, Zbieg, \& Oleszkowicz, 2014). This may suggest that this type of mental activity will also be associated with the consequences of experienced traumatic events. Moreover, ruminations and reflection may constitute the mechanism by which personality influences PTG. This would be in line with the concept of the transactional model, according to which PTG is produced by the interaction of stable human traits and traumatic events. Personality has a stable role in prediction of positive posttraumatic changes, and this effect is likely to occur through the mediating impact of cognitive evaluation and response (Park $\&$ Folkman, 1997). The lack of such research in Poland justifies the need for exploration of the relationship between personality, rumination and PTG.

The main purpose of the present study was to establish the mediating role of ruminations (both as a disposition and as a reaction to an experienced situation) in the relation between personality and PTG in cancer patients. The study addresses the following research questions:

- What degree of positive outcomes resulting from the experienced event did the subjects demonstrate?
- Are personality and ruminations associated with the intensity of PTG?

- Is personality related to ruminations?

- Do ruminations mediate the relation between personality and PTG?

Taking into account models of PTG (Calhoun \& Tedeschi, 2006; Calhoun, Cann, \& Tedeschi, 2010) it may be supposed that both personality and rumination will be related to PTG and that ruminations, both dispositional and about an experienced situation, will mediate the relationship between personality and PTG.

\section{PARTICIPANTS AND PROCEDURE}

Participants for the study were recruited among patients of the health care centres dealing with facial reconstruction in Lodz, Poland. These people were diagnosed with a form of cancer in the craniofacial area (i.e. lip, palate, parotid gland, eye, nasopharynx, nasal cavity, paranasal sinuses and inner ear). This type of cancer constitutes $4.50 \%$ of all malignant tumours occurring in Poland and is rarely the subject of research. Patients experienced visible changes in the craniofacial region, which resulted in the need to reconstruct the face.

Seventy patients were recruited, out of which 60 completed the measurement tools and admitted that the experience of cancer was a traumatic situation for them. The examination took place during the medical appointment after the surgery which was performed earlier. The data were collected in the period from January to June 2016. The study was approved for ethical treatment by the appropriate bioethics committee $^{1}$. The participants were informed of the aim of the study and were assured of their anonymity. Written consent forms were signed by the participants prior to the study.

The age range of the respondents was 18-78 years $(M=50.40, S D=17.74)$. The majority of the respondents were women $(68.30 \%)$. The subjects were surveyed using the Posttraumatic Growth Inventory, the NEO Five-Factor Inventory, the Rumination-Reflection Questionnaire and Event-Related Rumination Inventory.

The Posttraumatic Growth Inventory (PTGI), developed by Tedeschi and Calhoun (1996) and adapted to Polish conditions by Ogińska-Bulik and Juczyński (2010), consists of 21 statement describing various positive changes resulting from the experienced of a traumatic event ("I have changed my priorities regarding that which is important in life"). The participants respond to the statements providing answers from 0 (not having experienced this change) to 5 (having experienced this change to a great degree). The Polish version of the PTGI measures four factors constituting posttraumatic growth: changes in self-perception, 
changes in relations with others, greater appreciation of life and spiritual changes. The reliability coefficient of the Polish version the PTGI is high (Cronbach's $\alpha$ $=.93$ for total score and for individual subscales: .87 , $.85, .73, .63)$ and similar to that of the original version.

The NEO Five-Factor Inventory (NEO-FFI), developed by Costa and McRae (1989), in the Polish adaptation by Zawadzki, Strelau, Szczepaniak, and Sliwińska (1998), was used to measure five dimensions of personality: neuroticism, extraversion, openness to experience, agreeableness and conscientiousness. It comprises 60 statements ("I am not a worrier"), which are rated on a five-point scale from 1 (decidedly disagree) to 5 (completely agree). The psychometric profile of the Polish adaptation of the NEO-FFI is satisfactory (Cronbach's $\alpha$ values are from .60 to .82).

Carter (2010) prepared a modified version of the Rumination-Reflection Questionnaire (RRQ) developed by Trapnell and Campbell (1999). a Polish adaptation of this tool was developed by Radon (2014). The tool includes 13 items (e.g., "My attention is often so focused on the different characteristics of my person that I cannot get away from it"), to which the examined person has to rate, using a 5-step scale from 1 (I do not agree) up to 5 (I agree completely). The questionnaire makes it possible to evaluate two aspects of ruminations concerning the world and self, the negative, called ruminations, including inflexible patterns of thought and feeling, and positive, called reflection, which rates the tendency to analyse and solve problems. The questionnaire obtained satisfactory, although lower than the original version, psychometric parameters. The Cronbach $\alpha$ index for rumination is .77 and for reflection .79.

The Event Related Rumination Inventory (ERRI), developed by Cann and co-workers (2011) and adapted to Polish conditions by Ogińska-Bulik and Juczyński (2015), consists of two subscales with 10 items each. The first ("I thought about the event when I did not mean to") covers intrusive ruminations, which are uncontrolled, and the second one ("I thought about whether I could find meaning from my experience") covers deliberate (reflective) ones. The respondents rate the items on a 4-point Likert scale from 0 (not at all) to 3 (often). The scores are computed separately for each subscale. The inventory has very good psychometric properties. In the Polish version Cronbach's $\alpha$ is .96 for intrusive ruminations and .92 for deliberate ruminations.

Statistical analyses included determining the means of analysed variables, differentiation of posttraumatic growth according to sex, age and time since the diagnosis of the disease, establishing relationships between variables using correlation coefficients and determining the mediating role of ruminations in the relationship between personality and posttraumatic growth, using multiple mediations analyses with the PROCESS procedure.

\section{RESULTS $^{2}$}

In Table 1 means of the analysed variable are presented.

The mean of PTG demonstrated by the subjects corresponded to a value of five sten, which indicates a medium result. According to the norms designed for the Polish version of the PTGI (Ogińska-Bulik \& Juczyński, 2010), the results indicate that $33.30 \%$ of those studied demonstrated a low level of PTG, $43.40 \%$ a medium level and $23.30 \%$ a high level.

Sex had a statistically significant influence on the intensity of positive posttraumatic changes, i.e. PTG (men: $M=51.52, S D=20.62$; women: $M=62.56$, $S D=17.00, t=-2.18, p=.050)$. The time from the occurrence of the disease was not associated with the degree of PTG (shorter, i.e. less than five years: $M=62.59, S D=19.12$; longer, i.e. five years and over: $M=55.03, S D=17.85)$. Age was not associated with the level of PTG $(r=.03)$.

The means of rumination and reflection, assessed by RRQ, are similar to the means obtained by Carter (2010). The means of ruminations about the experienced situation, assessed by the ERRI, are similar to the results obtained by Cann et al. (2011) and in Polish standardization research (Ogińska-Bulik \& Juczyński, 2015). In both types of ruminations (intrusive, deliberate) the examined persons, regardless of sex, obtained the results of 5-6 sten.

Only two dimensions of the Big Five model were found to be related to positive posttraumatic chang-

Table 1

Level of analysed variables

\begin{tabular}{lcc}
\hline Variable & $M$ & $S D$ \\
\hline Posttraumatic growth - general & 59.41 & 18.77 \\
$\quad$ changes in self-perception & 24.32 & 9.02 \\
$\quad$ changes in relations with & 20.32 & 7.27 \\
$\quad$ others & & \\
$\quad$ appreciation of life & 10.37 & 3.63 \\
$\quad$ changes in spiritual sphere & 4.40 & 2.74 \\
Neuroticism & 21.95 & 7.53 \\
Extraversion & 27.63 & 6.84 \\
Openness to experience & 27.28 & 5.34 \\
Agreeableness & 31.02 & 4.45 \\
Conscientiousness & 32.28 & 6.95 \\
Rumination (RRQ) & 15.82 & 4.69 \\
Reflection (RRQ) & 20.10 & 4.65 \\
Intrusive rumination (ERRI) & 16.83 & 9.56 \\
Deliberate rumination (ERRI) & 17.33 & 7.56 \\
\hline
\end{tabular}

The role of ruminations in the relation between personality and PTG 
es. Neuroticism is negatively and conscientiousness is positively related to PTG - total. Posttraumatic growth also correlates with reflection, measured by the RRQ, and two types of ruminations about the experienced disease, measured by the ERRI, but higher values of correlation coefficients were obtained for deliberate than intrusive ruminations (Table 2).

Neuroticism revealed a positive association with rumination, measured by RRQ, and intrusive ruminations about the experienced disease, measured by the ERRI (Table 3). In turn, openness to experience positively correlates with reflection (RRQ) and negatively with intrusive ruminations (ERRI). Conscientiousness appeared to be related only to reflection.

Then the role of ruminations in the relation between personality dimensions and PTG was analysed. Multiple mediation analysis with the PROCESS procedure was used. It was based on the bootstrapping procedure proposed by Preacher and Hayes (Preacher \& Hayes, 2008; Cichocka \& Bilewicz, 2010), with 5000 bootstrap samples. This method is more useful than the commonly used Sobel test. It has more explanatory power, does not require an assumption about normality of variable distributions and can be conducted in relatively small trials (Cichocka \& Bilewicz, 2010).

Mediation analysis allows a more complex model structure to be checked, and to determine whether the variables acting as the predictors (in this case the personality dimensions) are associated with the dependent variable (PTG), via variables (rumination/ reflection treated in terms of disposition and intrusive/deliberate ruminations about the experienced disease) that serve as the mediators. The mediating effect occurs when the mediator decreases the predictive value of the independent variable for the dependent variable. In the case of increasing these properties we have an effect of suppression.

The following figures show models that indicate the role of ruminations in the relationship between neuroticism and PTG. Bias-corrected 95\% confidence intervals were conducted. Confidence intervals that do not contain zero indicate a significant indirect effect. In subsequent figures, $\beta c$ denotes the predictive

Table 2

Correlation coefficients between personality dimensions, ruminations and PTG

\begin{tabular}{lccccc}
\hline & PTG-total & F. 1 & F. 2 & F. 3 & F. 4 \\
\hline Neuroticism & $-.28^{*}$ & $-.33^{*}$ & -.24 & -.09 & .13 \\
Extraversion & .20 & $.31^{*}$ & .16 & .06 & -.22 \\
Openness to experience & .14 & $.27^{*}$ & .07 & .01 & $-.26^{*}$ \\
Agreeableness & .19 & .18 & .21 & .16 & .04 \\
Conscientiousness & $.39^{* *}$ & $.46^{* * *}$ & .24 & $.27^{*}$ & $.32^{*}$ \\
Rumination (RRQ) & .10 & .12 & -.01 & .09 & $.27^{*}$ \\
Reflection (RRQ) & $.26^{*}$ & $.38^{* *}$ & .11 & .12 & -.01 \\
Intrusive rumination (ERRI) & $.39^{* *}$ & .19 & $.38^{* *}$ & $.55^{* * *}$ & $.40^{* *}$ \\
Deliberate rumination (ERRI) & $.47^{* * *}$ & $.35^{* *}$ & $.41^{* * *}$ & $.55^{* * *}$ & $.29^{*}$ \\
\hline
\end{tabular}

Note ${ }^{* * *} p<.001,{ }^{* *} p<.01,{ }^{*} p<.05 ;$ F. 1. Changes in self-perception; F. 2. Changes in relations with others; F.3. Appreciation of life; F.4. Changes in spiritual sphere.

Table 3

Correlation coefficients between personality and ruminations

\begin{tabular}{lcccc}
\hline & $\begin{array}{c}\text { Rumination } \\
\text { (RRQ) }\end{array}$ & $\begin{array}{c}\text { Reflection } \\
\text { (RRQ) }\end{array}$ & $\begin{array}{c}\text { Intrusive } \\
\text { rumination } \\
(\text { ERRI) }\end{array}$ & $\begin{array}{c}\text { Deliberate } \\
\text { rumination } \\
(\text { ERRI) }\end{array}$ \\
\hline Neuroticism & $.48^{* * *}$ & -.03 & $.34^{* *}$ & .12 \\
Extraversion & -.04 & .12 & -.24 & .11 \\
Openness to experience & .01 & $.35^{* *}$ & $-.26^{*}$ & .17 \\
Agreeableness & -.01 & .07 & .05 & .12 \\
Conscientiousness & -.03 & $.26^{*}$ & -.01 & .06 \\
\hline Note. ${ }^{* * *} p<.001,{ }^{* *} p<.01,{ }^{*} p<.05$. & & & &
\end{tabular}


values of the independent variable before the introduction of mediators, and $\beta c^{\prime}$ denotes the value of the predictive variable after the introduction of mediators. Three models were found to be significant and all of them denote neuroticism.

The presented model of linkage between variables seems to be quite complex. As can be seen in Figure 1, a direct negative relationship - although weak - between neuroticism and posttraumatic growth, after the introduction of mediators, was found. However, the strength of this relationship is increasing, which is evidence of the effect of suppression. Neuroticism is positively associated with intrusive ruminations, but it does not relate to reflection. Reflection and intrusive ruminations about the disease favour positive posttraumatic changes, with a higher incidence of ruminations in prediction of posttraumatic growth. The mediators included in the analysis are not related. The model indicates, on the one hand, that neuroti- cism inhibits growth after trauma, and, on the other hand, that reflection and a tendency to intrusive ruminating about the experienced disease may increase the occurrence of positive posttraumatic changes. Reflection, understood as a disposition, seems to help to reap benefits from trauma.

Similar relationships were observed for one of the dimensions of PTG, i.e. positive changes in relations with others (Figure 2).

There is a negative direct relationship between neuroticism and positive changes in relations with others, but after introduction of the mediators the strength of this relationship increases, which indicates an effect of suppression. Neuroticism is positively related to intrusive ruminations but not to reflection. The analysed mediators are not related. Intrusive thoughts about the experienced disease favour the occurrence of positive changes in relations with others.

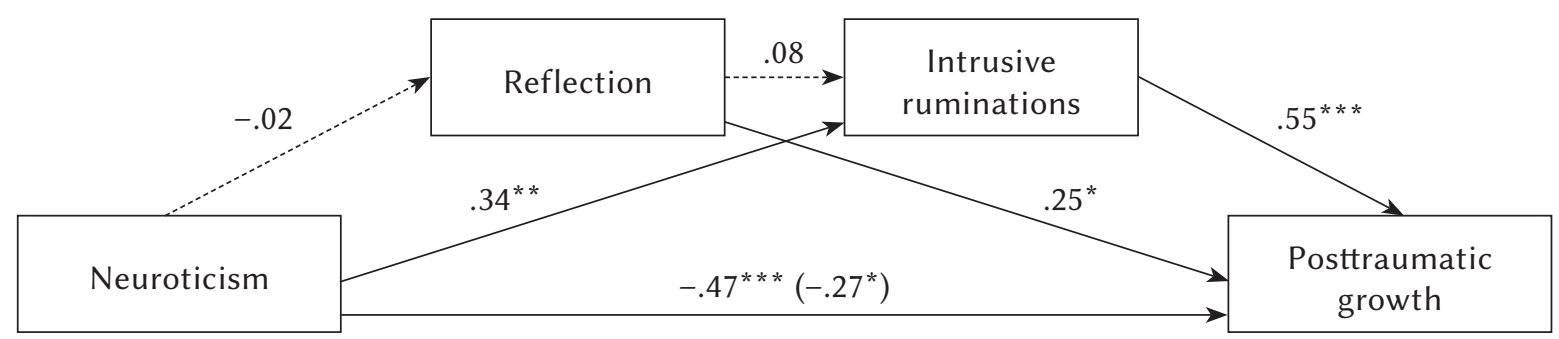

$R^{2}=.39, F=4.87, p<.05$

Figure 1. Model of double mediation between neuroticism, reflection, intrusive ruminations about the disease and PTG.

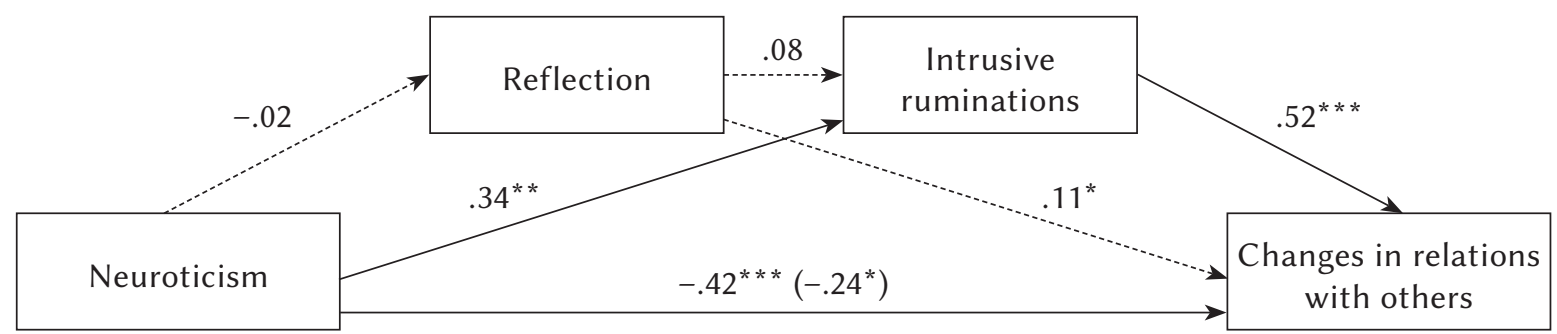

$R^{2}=.31, F=8.33, p<.001$

Figure 2. Model of double mediation between neuroticism, reflection, intrusive ruminations about the disease and positive changes in relations with others.

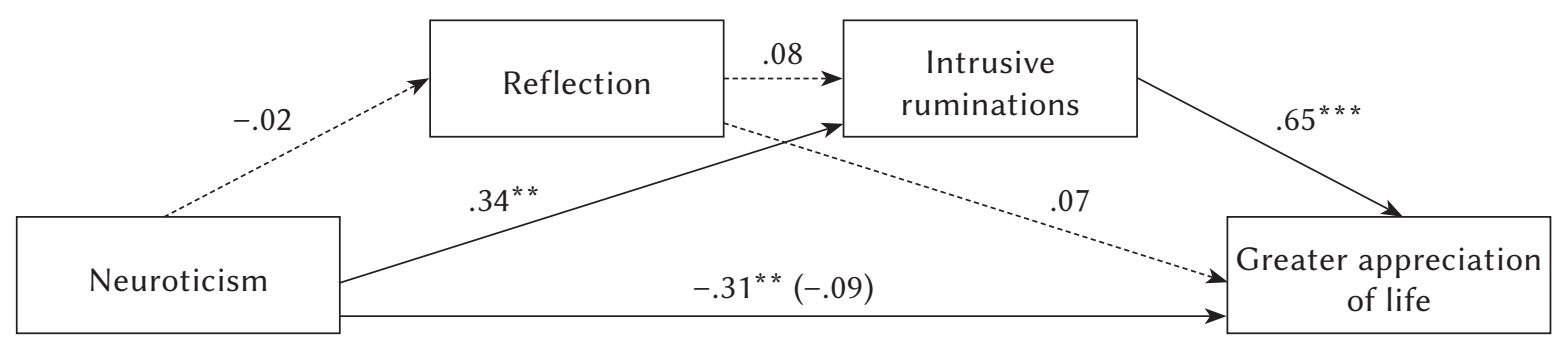

$R^{2}=.39, F=12.11, p<.001$

Figure 3. Model of double mediation between neuroticism, reflection, intrusive ruminations about the disease and greater appreciation of life. 
The next model (Figure 3) indicates the lack of a direct relationship between neuroticism and greater appreciation of life. Introduction of mediators causes that this relationship becomes significant, which indicates an effect of suppression. Neuroticism is related to intrusive ruminations but not to reflection. The analysed mediators are not related. Intrusive thinking about the experienced disease favours greater appreciation of life.

Nina Ogińska-Bulik

The findings indicate that the experience of cancer may be a source of PTG. No subjects were observed to have any positive change resulting from the struggle with the disease, while $23.30 \%$ of them demonstrated a high level of PTG. Women demonstrated a slightly higher level of PTG than men, which is consistent with the results of other studies (Helgeson, Reynolds, \& Tomich, 2006; Ogińska-Bulik \& Juczyński, 2010; Vishnevsky, Cann, Calhoun, Tedeschi, \& Demakis, 2010). Women are more prone to perceiving threat and reveal a higher level of PTSD. In turn, higher perceived threat may lead to greater upheaval of an individual's assumptive world, which favours the occurrence of PTG (Vishnevsky et al., 2010). Women are probably more likely to be involved in ruminating processes, especially those of a deliberate character. A tendency to ruminate on constructive issues, such as increased awareness of personal strengths, has been suggested as a mechanism leading to PTG (Cann et al., 2011; Vishnevsky et al., 2010). Additionally, women are more likely to utilize such coping strategies as positive reappraisal, acceptance or turning to religion, which favour the occurrence of PTG (Vishnevsky et al., 2010).

Age and time since the diagnosis of cancer do not differentiate the level of PTG. The findings are consistent with other studies indicating prevalence of PTG in people struggling with cancer (Bellizzi \& Blank, 2006; Carboon et al., 2005; Mystakidou et al., 2008; Ogińska-Bulik, 2016; Park et al., 2010). They also confirm the Tedeschi and Calhoun concept of PTG (Tedeschi \& Calhoun, 1996, 2004), which encompasses the presence of positivity in the face of a traumatic situation.

On the other hand, Casellas-Grau, Ochoa, and Ruini (2017) formulate the question whether PTG might be the best model to capture a positive reaction following medical-related trauma, and their beneficial consequences in mental health. To this question, so far there is no answer. This indicates the need for further research, with wider use of clinical correlates of PTG.

Two dimensions of the Big Five model appeared to be related to positive posttraumatic changes. Neuroticism is negatively and conscientiousness is positively related to PTG. The results partly confirmed data obtained by other researchers (Linley \& Joseph, 2004; Ogińska-Bulik, 2017a). However, it is worth noting that among the personality factors that seem to favour the occurrence of PTG, above all extraversion and openness to experience are listed. The present study indicates that these dimensions of personality are positively, although poorly, related to one domain of PTG, i.e. positive changes in self-perception. However, openness to experience was found to be the factor which reduces positive changes in the spiritual sphere. This indicates that the relationships between personality and PTG are complex and that in analysing these relations one should take into account not only the overall outcome, but also the particular domains of growth after trauma.

Reflection (reflective ruminating), understood in terms of disposition, and both types of event-related ruminations, particularly deliberate thinking, are positively related to posttraumatic changes. The results are consistent with other data concerning various types of traumatic situations (Cann et al., 2011; Stockton, Hunt, \& Joseph, 2011; Taku, Kilmer, Cann, Tedeschi, \& Calhoun, 2012; Wu, Zhou, Wu, \& An, 2015) and results obtained from oncological patients (Chan et al., 2011; Morris \& Shakespeare-Finch, 2011). The obtained results also confirm the model of PTG (Calhoun \& Tedeschi, 2006; Calhoun et al., 2010).

Moreover, some of the personality dimensions were found to be related to ruminations. Neuroticism is positively related to rumination, measured by the RRQ, and event-related intrusive ruminations, measured by the ERRI. Openness to experience positively correlates with reflection and intrusive ruminations. Conscientiousness is associated with reflection.

The role of event-related ruminating turned out to be more significant than the relatively stable human properties, including personality dimensions and dispositional rumination/reflection. It was partly confirmed by the results of mediation analyses, which refer to the negative relationship between neuroticism and PTG; however, this relationship seems to be complex. Intrusive ruminations and reflection appeared to be suppressors in the relationship between neuroticism and PTG. Intrusive ruminations were also suppressors in relations between neuroticism and two dimensions of PTG, i.e. positive changes in relations with others and a greater appreciation of life. It indicates, on the one hand, that neuroticism inhibits growth after trauma, and, on the other hand, that reflection and event-related intrusive ruminations increase the intensity of positive posttraumatic changes. Event-related intrusive thinking seems to play a more important role than reflection, treated as a disposition.

The obtained results confirmed that ruminations and reflection may be regarded as a mechanism by which personality influences PTG, which is consistent with the concept of the transactional model 
(Park \& Folkman, 1997). The results are partly in line with data obtained by An et al. (2017), from a study conducted on adolescents who survived the Wenchuan earthquake. They stated that the relationship between personality (according the Big Five model) and PTG is mediated by cognitive coping. However, this relationship did not concern neuroticism.

The results indicating the significant role of intrusive ruminations about the experienced situation may seem controversial. It could be rather expected that deliberate ruminations will primarily be conducive to the occurrence of positive posttraumatic changes. However, the role of both types of ruminations seems to be important in occurrence of PTG.

The authors of a model of PTG (Calhoun \& Tedeschi, 2006; Calhoun et al., 2010) stated that although intrusive ruminations favour mainly the occurrence of PTSD, they may also foster positive changes, especially in appreciation of life and the spiritual sphere. Intrusive thinking, which is a natural response after experiencing a traumatic event, may represent a prelude to deliberate ruminations, acting to find ways of coping with the situation. In other words, intrusive ruminations provide the survivors an opportunity for further cognitive processing of the traumatic event, which may result in PTG.

The adaptive role of intrusive thoughts in the occurrence of positive posttraumatic changes is also stressed by Brooks, Graham-Kevan, Robinson, and Lowe (2018), who showed that intrusive thoughts mediated the relationship between interpersonal trauma and PTG.

It is also important to note that ruminations of the experienced event, especially intrusive, may initially be associated with greater feelings of distress and negative emotions. However, later on, when intrusive ruminations change into deliberate ruminations, they favour the search for ways of coping with the event and its associated emotions, and in effect serve to work through the trauma and foster positive changes. The occurrence of deliberate ruminations, however, demands the passage of time (Helgeson et al., 2006). The time is needed to re-analyse the traumatic situation, and give it sense and new meaning, which as a consequence may lead to the occurrence of PTG.

It is important to mention that the significance of personality and ruminations, in particular, in the fostering of positive effects of trauma may also be associated with the human skills for coping. This confirms studies indicating a positive association between ruminations and coping strategies favouring the appearance of growth, such as positive reframing, adopting problem-focussed strategies, turning to religion or giving sense to the experienced event (Cann et al., 2011). In studies involving people infected with HIV (Ogińska-Bulik, 2017b), in which two types of ruminations were considered, it was found that deliberate ruminations played a predictive role for active coping, planning, positive reframing and seeking social support. In turn, intrusive ruminations were predictors of venting, behavioural disengagement and self-blame.

The present study has some limitations. It is of a cross-sectional nature, which does not allow the cause-effect relationship to be unequivocally evaluated. It was performed on subjects who had experienced one type of cancer (craniofacial cancer) and at various times. In addition, the study did not test whether the subjects had undergone any other events of a traumatic nature, and any changes were evaluated on a self-reporting basis, which may influence the results to some degree. Other confounding variables were not considered in the study. However, despite the limitations, the obtained results add new content regarding the effect of a negative life event, associated with experiencing a life-threatening disease, on psychosocial functioning of man. It may serve as inspiration for further studies, which should examine the role of the strategies chosen for coping with the experienced event.

The findings may also have significance in practice, particularly in crisis interventions and in prophylactic programmes. Such programmes should aim to build the skills to "work through" the experienced trauma by reducing anxiety, encouraging analysis of emerging thoughts and emotions and expressing them. The effectiveness of this type of therapy is emphasized by Foa, Chrestman, and Gilboa-Schechtman (2014). Developing competence in coping with traumatic experiences may also be of value. It is important to remember that the occurrence of PTG also represents an opportunity to build resistance and a better ability to cope with future life challenges.

The findings allow us to formulate the following conclusions:

- Experiencing cancer may be related to positive posttraumatic changes, especially in the form of greater appreciation of life.

- Personality dimensions are poorly linked with positive posttraumatic changes; neuroticism correlates negatively and conscientiousness positively with PTG.

- Ruminations about the experienced disease seem to play a more important role than personality in the occurrence of positive posttraumatic changes.

- Intrusive ruminating may strengthen the negative relationship between neuroticism and PTG.

\section{ENDNOTES}

1 The study was performed by a Master's seminar participant.

2 The results of the research were presented at the $36^{\text {th }}$ Congress of Polish Psychological Association, Gdansk, Poland, 2017.
The role of ruminations in the relation between personality and PTG 


\section{REFERENCES}

An, Y., Ding, X., \& Fu, F. (2017). Personality and posttraumatic growth of adolescents 42 months after the Wenchuan earthquake: a mediated model. Frontiers in Psychology, 8, 2152. https://doi. org/10.3389/fpsyg.2017.02152

Bellizzi, K. M., \& Blank, T. O. (2006). Predicting posttraumatic growth in breast cancer survivors. Health Psychology, 25, 47-56.

Nina Ogińska-Bulik

Brooks, M., Graham-Kevan, N., Robinson, S. J., \& Lowe, M. (2018). Trauma characteristics and posttraumatic growth: The mediating role of avoidance, coping, intrusive thoughts and social support. Psychological Trauma. Theory Research Practice and Policy. https://doi.org/10.1037/tra0000372

Calhoun, L. G., \& Tedeschi, R. G. (1998). Posttraumatic growth: Future directions. In R. G. Tedeschi, C. L. Park, \& L. G. Calhoun (eds.), Posttraumatic growth: Positive changes in the aftermath of crisis (pp. 1-23) New Jersey: Lawrence Erlbaum Associates.

Calhoun, L. G., \& Tedeschi, R. G. (2006). The foundations of posttraumatic growth: An expanded framework. In L. G. Calhoun \& R. G. Tedeschi (eds.), Handbook of posttraumatic growth: Research and practice (pp. 3-23). New Jersey: Lawrence Erlbaum Associates.

Calhoun, L. G., Cann, A., \& Tedeschi, R. G. (2010). The posttraumatic growth model: Sociocultural considerations. In T. Weiss \& R. Berger (eds.), Posttraumatic growth and culturally competent practice: Lessons learned from around the globe (pp. 1-14) New Jersey: John Wiley \& Sons.

Cann, A., Calhoun, L. G., Tedeschi, R. G., Triplett, K. N., Vishnevsky, T., \& Lindstrom, C. M. (2011). Assessing posttraumatic cognitive processes: the Event Related Rumination Inventory. Anxiety, Stress and Coping, 24, 137-156.

Carboon, I., Anderson, V., Pollard, A., Szer, J., \& Seymour, J. (2005). Posttraumatic growth following a cancer diagnosis: do world assumptions contribute? Traumatology, 11, 269-283.

Carter, J. A. (2010). Worry and rumination: Measurement invariance across gender. Doctoral thesis, Utah State University. digitalcommons.usu.edu/ cgi/viewcontent.cgi?article $=1801 \&$ context $=$ etd.

Casellas-Grau, A., Ochoa, C., \& Ruini, C. (2017). Psychological and clinical correlates of posttraumatic growth in cancer: a systematic and critical review. Psycho-Oncology, 26, 2007-2018. https://doi. org/10.1002/pon.4426

Chan, M. W., Ho, S. M., Tedeschi, R. G., \& Leung, C. W. (2011). The valence of attentional bias and cancer-related rumination in posttraumatic stress and posttraumatic growth among women with breast cancer. Psycho-Oncology, 20, 544-552.

Cichocka, A., \& Bilewicz, M. (2010). Co się kryje w nieistotnych efektach statystycznych? Możli- wości zastosowania analizy supresji w psychologii społecznej [What is hidden in nonsignificant effects? Application of suppression analysis in social psychology]. Psychologia Spoteczna, 5, 191-198.

Cordova, M. J., Studs, J. L., Hann, D. M., Jacobsen, P. B., \& Andrykowski, M. A. (2000). Symptom structure of PTSD following breast cancer. Journal of Traumatic Stress, 13, 301-309.

Cormio, C., Muzzatti, B., Romito, F., Mattioli, V., \& Annunziata, M. A. (2017). Posttraumatic growth and cancer: a study 5 years after treatment. Support Care Cancer, 25, 1087-1096. https://doi. org/10.1007/s00520-016-3496-4

Costa, P. J., \& McCrae, R. R. (1989). NEO-PI/FFI. Manual supplement. Odessa, FL: Psychological Assessment Resources.

Foa, E. B., Chrestman, K. R., \& Gilboa-Schechtman, E. (2014). Przedłużona ekspozycja w terapii PTSD nastolatków. Emocjonalne przetwarzanie traumatycznych doświadczeń [Extended exposure in PTSD therapy for teenagers. Emotional processing of traumatic experiences]. Sopot: Gdańskie Wydawnictwo Psychologiczne.

Helgeson, V., Reynolds, K., \& Tomich, P. (2006). A meta-analytic review of benefit finding and growth. Journal of Consulting and Clinical Psychology, 74, 797-816.

Janoff-Bulman, R. (2006). Schema-change perspectives on posttraumatic growth. In L. G. Calhoun \& R. G. Tedeschi (eds.). Handbook of posttraumatic growth - research and practice (pp. 81-99). New Jersey: Lawrence Erlbaum Associates.

Joormann, J., Dkane, M., \& Gotlib, I. (2006). Adaptive and maladaptive components of rumination? Diagnostic specificity and relation to depressive biases. Behavior Therapy, 37, 269-280.

Karanci, A. N., Işıklı, S., Aker, A. T., Gül, E. I, Erkan, B. B., Özkol, H., \& Güzel, H. Y. (2012). Personality, posttraumatic stress and trauma type: Factors contributing to posttraumatic growth and its domains in a Turkish community sample. European Journal of Psychotraumatology, 3. http://dx.doi. org/10.3402/ejpt.v3i0.17303

Linley, P. A., \& Joseph, S. (2004). Positive change following trauma and adversity: a review. Journal of Traumatic Stress, 17, 11-21.

Michael, T., Halligan, S. L., Clark, D. M., \& Ehlers, A. (2007). Ruminations in posttraumatic stress disorder. Depression and Anxiety, 24, 307-317. https:// doi.org/10.1002/da.20228

Morris, B., \& Shakespeare-Finch, J. (2011). Rumination, post-traumatic growth, and distress: structural equation modeling with cancer survivors. Psycho-Oncology, 20, 1176-1183.

Mystakidou, K., Tsilika, E., Parpa, E., Galanos, A., \& Vlahos, L. (2008). Post-traumatic growth in advanced cancer patients receiving palliative care. British Journal of Health Psychology, 13, 633-646. 
Nolen-Hoeksema, S. (2000). The role of rumination in depressive disorders and mixed depressive/anxiety symptoms. Journal of Abnormal Psychology, 109, 504-511.

Ogińska-Bulik, N. (2010). Potraumatyczny rozwój w chorobie nowotworowej - rola prężności [Posttraumatic growth In cancer disease - the role of resiliency]. Polskie Forum Psychologiczne, 15 125-139.

Ogińska-Bulik, N. (2015). Dwa oblicza traumy negatywne i pozytywne skutki zdarzeń traumatycznych u pracowników stużb ratowniczych [Two faces of trauma - negative and positive effects of traumatic events in employees of emergency services]. Warsaw: Wyd. Difin.

Ogińska-Bulik, N. (2016). Rola ruminacji w występowaniu pozytywnych zmian potraumatycznych u osób zmagających się z chorobami nowotworowymi [The role of rumination in occurrence of posttraumatic positive changes in people struggling with cancer]. Psychoonkologia, 20, 1-8. https://doi.org/10.5114/pson.2015.55305

Ogińska-Bulik, N. (2017a). Potraumatyczny wzrost u chorych onkologicznie - rola osobowości i ruminacji [Posttraumatic growth among people with oncological disease - the role of personality and rumination]. Psychiatria, 14, 53-60.

Ogińska-Bulik, N. (2017b). Rumination and coping with stress resulting from HIV infection. Przeglad Psychologiczny, 60, 211-222.

Ogińska-Bulik, N., \& Juczyński, Z. (2010). Rozwój potraumatyczny - charakterystyka i pomiar [Posttraumatic growth - characteristic and measurement]. Psychiatria, 7, 129-142.

Ogińska-Bulik, N., \& Juczyński, Z. (2015). Inwentarz Ruminacji o Negatywnym Zdarzeniu - polska adaptacja the Event Related Rumination Inventory [The Polish adaptation of the event related rumination inventory]. Przeglad Psychologiczny, 58, 383-400.

Park, C. L., \& Folkman, S. (1997). Stability and change in psychosocial resources during caregiving and bereavement in partners of men with aids. Journal of Personality, 65, 421-447.

Park, C. L., Chmielewski, J., \& Blank, T. O. (2010). Posttraumatic growth: Finding positive meaning in cancer survivorship moderates the impact of intrusive thoughts on adjustment in younger adults. Psycho-Oncology, 19, 1139-1147.

Preacher, K., \& Hayes, A. F. (2008). Asymptotic and resampling strategies for assessing and comparing indirect effects in multiple mediator models. Behavior Research Methods, 40, 879-891. https:// doi.org/10.3758/BRM.40.3.879

Radoń, S. (2014). Kwestionariusz Ruminacji-Refleksyjności - polska adaptacja the RuminationReflection Questionnaire [Construction and validation of the Polish version of the Rumina-
tion-Reflection Questionnaire]. Psychoterapia, 169, 61-72.

Salsman, J. M., Segerstrom, S. C., Brechting, E. H., Carlson, C. R., \& Andrykowski, M. A. (2009). Posttraumatic growth and posttraumatic stress disorder symptomatology among colorectal cancer survivors: a 3 month longitudinal examination of cognitive processing. Psycho-Oncology, 18, 30-41.

Shakespeare-Finch, J., Gow, K., \& Smith, S. (2005). Personality, coping and posttraumatic growth in emergency ambulance personnel. Traumatology, $11,325-334$.

Shelby, R., \& Golden-Kreutz, D. (2008). PTSD diagnoses, subsyndromal symptoms and commorbidity contribute to impairments for breast cancer survivors. Journal of Traumatic Stress, 21, 165-172.

Słowińska, A., Zbieg, A., \& Oleszkowicz, A. (2014). Kwestionariusz Ruminacji-Refleksyjności (RRQ) Paula D. Trapnella i Jennifer D. Campbell - polska adaptacja metody [Paul D. Trapnell and Jennifer D. Campbell's Rumination-Reflection Questionnaire (RRQ) - Polish adaptation of the measure]. Polskie Forum Psychologiczne, 19, 457-478.

Stockton, H., Hunt, N., \& Joseph, S. (2011). Cognitive processing, rumination and posttraumatic growth. Journal of Traumatic Stress, 24, 85-92.

Taku, K., Kilmer, R. P., Cann, A., Tedeschi, R. G., \& Calhoun, G. (2012). Exploring posttraumatic growth in Japanese youth. Psychological trauma: Theory, Research, Practice and Policy, 4, 411-419.

Tashiro, T., \& Frazier, P. (2003). "I'll never be in a relationship like that again”. Personal growth following romantic relationship breakups. Personal Relationship, 10, 113-128.

Tedeschi, R. G., \& Calhoun, L. G. (1996). The PostTraumatic Growth Inventory: Measuring the positive legacy of trauma. Journal of Traumatic Stress, 9, 455-471.

Tedeschi, R. G., \& Calhoun, L. G. (2004). Posttraumatic growth: Conceptual foundations and empirical evidence. Psychological Inquiry, 15, 1-8.

Trapnell, P. D., \& Campbell, J. D. (1999). Private consciousness and the Five-Factor Model of Personality: Distinguishing rumination from reflections. Journal of Personality and Social Psychology, 76, 284-304.

Vishnevsky, T., Cann, A., Calhoun, A., Tedeschi, R., \& Demakis, G. (2010). Gender differences in selfreported posttraumatic growth: a meta-analyses. Psychology of Women Quarterly, 34. journals. sagepub.com/doi/10.1111/j.1471-6402.2009.01546.

Wu, X., Zhou, X., Wu, Y., \& An, Y. (2015). The role of rumination in posttraumatic stress disorder and posttraumatic growth among adolescents after the Wenchuan earthquake. Fronties in Psychology, 4, 1335. https://doi.org/10.3389/fpsyg.2015.01335

Zawadzki, B., Strelau, J., Szczepaniak, P., \& Śliwińska, M. (1998). Inwentarz Osobowości NEO-FFI
The role of ruminations in the relation between personality and PTG 
Costy i McCrae [Personality Inventory NEO-FFI of Costa and McCrae]. Warsaw: Pracownia Testów Psychologicznych PTP.

Zwahlen, R., Krsna Rajandram, R., \& Jenewein, J. (2016). Post-traumatic growth in oral cavity cancer in relation to positive coping strategies, hope and optimism. In C. Martin, V. Preedy, \& V. Patel (eds.), Comprehensive guide to posttraumatic stress disorders (pp. 1783-1796). Cham: Springer.

Nina

Ogińska-Bulik 